DVASCULAR DISEASE

\title{
Combination therapy for PAD
}

$\begin{array}{ll}\text { The } & \begin{array}{l}\text { In patients with peripheral artery } \\ \text { disease (PAD) and intermittent } \\ \text { claudication, a combination therapy } \\ \text { of endovascular revascularization } \\ \text { followed by supervised exercise } \\ \text { therapy } \\ \text { achieved }\end{array} \\ \begin{array}{l}\text { results in faster and significantly } \\ \text { greater improvements in walking } \\ \text { quickly than } \\ \text { the supervised } \\ \text { exercise }\end{array} & \begin{array}{l}\text { compared with supervised exercise } \\ \text { only, according to results from the } \\ \text { alone ... }\end{array} \\ \begin{array}{l}\text { ERASE trial. } \\ \text { Patients with intermittent } \\ \text { claudication, a condition classically } \\ \text { associated with PAD, experience } \\ \text { substantial physical impairment and } \\ \text { disability, which results in reduced } \\ \text { quality of life. Current therapies to } \\ \text { manage intermittent claudication } \\ \text { include supervised exercise and } \\ \text { endovascular revascularization. } \\ \text { To assess the effectiveness of } \\ \text { combining both therapies, Myriam } \\ \text { Hunink and colleagues designed }\end{array}\end{array}$

a randomized clinical trial of 212 patients with PAD and intermittent claudication. The investigators randomly assigned the patients to receive either supervised exercise only, provided by physiotherapists specially trained in exercise for claudication, or a combination of endovascular therapy of selective stenting followed by supervised exercise. After 1 year, both groups improved their maximum treadmill walking distance; however, the group that received the combination therapy showed a significantly greater improvement in the maximum walking distance compared with the group that received only supervised exercise (mean difference between groups $282 \mathrm{~m}$; 99\% CI 60-505 m). The combination therapy also resulted in significantly greater improvement in pain-free walking and in disease-specific quality-of-life scores.

The combination therapy achieved results more quickly than the supervised exercise alone; the greatest difference between groups was at the 1-month follow-up. "By improving lower extremity blood flow, early percutaneous revascularization of the target lesion gives an impulse to patient mobility and quality of life in the short-term," explain the investigators. However, given that the advantages of the combination therapy decreased over time, further studies are needed to address the long-term benefits.

Irene Fernández Ruiz

ORIGINAL ARTICLE Fakhry, F. et al. Endovascular revascularization and supervised exercise for peripheral artery disease and intermittent claudication: a randomized clinical trial. JAMA 314, 1936-1944 (2015) 